RESEARCH ARTICLE

\title{
Microvascular Alterations in Hypertension and Vascular Aging
}

\author{
Carmine Savoia $^{1, *}$, Alleggra Battistoni ${ }^{1}$, Valentin Calvez $^{1}$, Vincezo Cesario ${ }^{1}$, Giulio Montefusco ${ }^{1}$ \\ and Antonio Filippini ${ }^{2}$
}

${ }^{I}$ Clinical and Molecular Medicine Department, Cardiology Unit, Faculty of Medicine and Psychology, Sant'Andrea Hospital, Sapienza University of Rome, Rome, Italy; ${ }^{2}$ Department of Anatomical Sciences, Histological, Legal Medical and Locomotor, Sapienza University of Rome, Rome, Italy

\begin{abstract}
Hypertension and aging are characterized by vascular remodelling and stiffness as well as endothelial dysfunction. Endothelial function declines with age, since aging is associated with senescence of the endothelium due to increased rate of apoptosis and reduced regenerative capacity of the endothelium. Different phenotypes of hypertension have been described in younger and adult subjects with hypertension. In younger patients, functional and structural alterations of resistance arteries occur as the earliest vascular alterations which have prognostic significance and may contribute to stiffness of large arteries through wave reflection. In individuals above age of 50 years as well as in subjects with long-lasting elevated blood pressure, vascular changes occur predominantly in conduit arteries which become stiffer. Activation of renin-angiotensin-aldosterone and endothelin systems plays a key role in endothelial dysfunction, vascular remodelling, and aging by inducing reactive oxygen species production, and promoting inflammation and cell growth.
\end{abstract}

Keywords: Vascular remodelling, media-to-lumen ratio, arterial stiffness, PWV, pulse pressure, endothelial dysfunction.

\section{INTRODUCTION}

Hypertension and cardiovascular disease increase with advancing age as shown in epidemiological studies. In particular, hypertension is an important risk factor for vascular senescence [1], resulting in premature cardiovascular disease.

In younger patients, increased peripheral vascular resistance is a common feature of essential hypertension. In presence of elevated blood pressure, vascular remodelling may occur over time particularly in the wall of large arteries through sustained stretch on the vascular wall which activates distinctive intracellular pathways [2], resulting in structural and functional alterations that eventually induce vascular stiffness, increased systolic blood pressure and may contribute to the progression of atherosclerosis [3].

*Address correspondence to this author at the Clinical and Molecular Medicine Department, Cardiology Unit, Sant'Andrea Hospital, Sapienza University of Rome, Via di Grottarossa 1037/1039, 00189 Rome, Italy;

Tel: +390633775561; Fax: +390633775061;

E-mail: carmine.savoia@uniroma1.it
In this regard, hypertensive vascular alterations and the age-associated changes in blood vessels share similar phenotypes, including structural changes (increased arterial wall thickness and stiffness as well as reduced compliance and lumen diameter) $[1,4]$, vascular inflammation $[5,6]$, and impaired endothelial function due to increased oxidative stress and decreased production of vasodilator agents such as nitric oxide (NO) [7].

Alterations in vascular tone at level of resistance arteries play an important role in the pathophysiology of hypertension by increasing peripheral resistance which is the most important site of pulse wave reflection that contributes to the stiffness of large arteries [3]. Impaired endothelial function is a common feature of hypertension and largely participates in the increased constriction of resistance arteries [8]. Also aging contributes to endothelial dysfunction which is characterized by reduced vasodilation and increased endotheliumdependent contraction, vascular permeability and a proinflammatory and prothrombotic phenotype. The latter is characterized by leucocyte-endothelial interactions that participate in vascular inflammation and increased adhesion and platelet aggregation [9-11], and it is recognized to be inde- 
pendently associated with increased cardiovascular risk [12]. The activation of inflammatory process in vascular and perivascular tissue is recognized as an important determinant in the pathophysiology of the structural alterations in the vascular wall of resistance and large arteries [13]. This may contribute to the development of the increased vascular resistance and vascular stiffness in large arteries as well as to the development of atherosclerosis [14, 15]. Vascular stiffness can be evaluated by carotid-femoral pulse wave velocity (PWV), that is associated with target organ damage and increased risk for cardiovascular morbidity and mortality [16].

It is well assessed that renin-angiotensin system (RAS) plays a key role in the pathophysiology of hypertension [17], contributing to oxidative stress, vascular inflammation, and thus to endothelial dysfunction.

This review will focus on the alterations that occur in the vascular wall particularly in resistance arteries (lumen diameter of $100-300 \mu \mathrm{m}$ ) in hypertension and vascular aging.

\section{ENDOTHELIAL DYSFUNCTION}

The endothelium may be considered the largest organ in the body as it is able to generate several factors that regulate vascular tone, vascular permeability, angiogenesis, and the response to inflammation. NO is the main modulator of endothelial function since it induces vasodilation, and exerts antioxidant and antinflammatory function [18], by inhibiting leukocyte adhesion [19], thrombocyte aggregation [20] and smooth muscle cell proliferation [21] .

Endothelial dysfunction is characterized by the impairment of endothelium-induced vasodilation, enhanced vasoconstriction and increased production of reactive oxygen species (ROS), thus it may contribute to the inflammation of the vascular wall $[9,11,16,17,22,23]$ and therefore to the remodelling of the arterial wall that typically occurs in hypertension as well in aging.

Endothelial dysfunction is one of the most important ageassociated cardiovascular changes [24, 25], that may occur in association with other important cardiovascular risk factors such as hypertension, diabetes dyslipidemia, and obesity.

Endothelium-dependent vasodilatation progressively declines with age as assessed by several clinical and experimental studies in different vascular beds including resistance arteries [25-29]. This may contribute to the development of hypertension as well to the hypertension related vascular alterations. Several putative mechanisms have been advocated to explain this effect including the breakdown of NO and other endothelial-derived substances such as prostacyclin and the endothelium-derived hyperpolarizing factor (EDHF) [30], independently of the structural changes in the vascular wall [31-38]. This, in turn, is associated with an enhanced reactivity to vasoconstrictors [39]. It has been reported that endothelial NO synthase (eNOS) expression and NO production decline with age [35, 40-42]. This may occur through the reduced eNOS mRNA expression and stability [43] due to the age-related decrease in shear stress [44] as well as by the age-related reduction of growth factors including human growth hormone $(\mathrm{GH})$ [45]. Interestingly, physical training as well as therapy with GH improves eNOS ex- pression and endothelial function in aged rats [42, 46] and humans [47-49].

Aging is associated with increased ROS production particularly in endothelial cells. Indeed, removal of the endothelium and the inhibition of the nicotinamide adenine dinucleotide phosphate (NADPH) oxidase (the main source of ROS in the vasculature) reduce vascular superoxide generation in the aorta of aged rats [50-55].

The increased production of ROS in the vasculature contributes to the reduced NO bioavailability and to the impaired relaxation $[35,38,50]$ particularly in the microcirculation [39]. This may occur through the uncoupling of the eNOS [35] and the generation of peroxynitrite [35, 56], which is a highly reactive oxidizing agent [57]. In fact, peroxynitrite is able to penetrate across cellular membranes and by substrate nitration, it may inactivate different enzymes, including free radical scavengers [35, 58]. Thus, the increased formation of peroxynitrite and reduced NO bioavailability during aging may inactivate antioxidative enzymes including superoxide dismutase (SOD) [56, 59]. Therefore, also cellular antioxidative defense systems are attenuated with aging [60]. This can further contribute to the enhanced production of ROS and endothelial dysfunction. Furthermore, it has been shown that the expression of inducible NO synthase (iNOS) is enhanced within the vascular wall of aged rats $[35,61]$. iNOS further promotes oxidative stress through the enhanced generation of superoxide anion and the formation of peroxynitrite $[57,62]$. ROS is also produced by mitochondria [63-69] and contributes to mitochondrial dysfunction which is progressively increased in vascular aging. In particular, it has been shown that mice lacking the mitochondrial p66Shc adaptor protein presented reduced production of intracellular ROS, increased NO bioavailability and improved endothelial dysfunction [70]. These features are associated with no age-dependent changes in iNOS as well as with prolonged life span [71]. Thus, the modulation of p66Shc function could be relevant for the protection from age-dependent endothelial dysfunction.

Vascular senescence is also associated with reduced capacity of the endothelium to regenerate [72-74]. Under normal conditions, endothelial cells present a low turnover rate [75], with aging endothelial cells expressing negative cell cycle regulators (i.e. p53 and p16) [76-79], and are characterized by impaired secretion of and/or sensitivity to growth factors which lead to growth arrest and senescence. Moreover, aged endothelial cells show also suppressed activity of telomerase reverse transcriptase [80-82], which is associated with shorter telomere length that is inversely related to chronological age in endothelial cells $[80,81]$. Interestingly, RAS activation and increased ROS production contribute to the reduction of the telomerase activity as well as to DNA damage and genomic instability. These are all-important promoters of cellular senescence [83-88] in the vasculature.

Also angiogenesis reduces with aging; in particular, endothelial senescence may be responsible for some processes that are typically observed in the elderly such as the impaired wound healing and angiogenesis [89]. In experimental model of senescence both in mice and humans, an imbalance between pro-angiogenic and anti-angiogenic factors has been 
described, particularly in microvascular endothelial cells. Specifically, the pro-angiogenic factors such as tissue inhibitor of metalloproteinase-2 (TIMP-2) [90] and the thrombospondin-2 [91] are increased, whereas, the anti-angiogenic factors such as vascular endothelial growth factor (VEGF) and transforming growth factor- $\beta 1$ (TGF- $\beta 1$ ) are reduced. These alterations are associated with reduced matrix deposition and reduced angiogenesis-associated inflammation which are required for angiogenesis. Moreover, also circulating endothelial progenitor cells (EPCs) are an important determinant for the potential capacity of endothelium regeneration as well as of endothelial function. EPCs are significantly reduced in aging [92] as well as in hypertensive conditions $[93,94]$. Finally, decreased EPCs numbers are also associated with decreased endothelial function [94] and arterial stiffness [95].

\section{REMODELLING OF RESISTANCE ARTERIES}

Vascular remodelling is typically found in resistance arteries of hypertensive individuals and is characterized by reduced vascular lumen with increased media thickness (i.e. increased media-to- lumen ratio - M/L-). These alterations may be functional, mechanical and/ or structural $[3,96]$. It has been well documented that $\mathrm{M} / \mathrm{L}$ is considered the most reproducible parameter of vascular remodelling of resistance arteries [3, 97]. A smaller lumen and the increased media thickness decrease circumferential tension and reduce media stress in order to protect the wall of the artery from the effects of elevated blood pressure. On the other hand, small decreases in the lumen diameter significantly increase resistance to blood flow, which can contribute to maintaining elevated blood pressure values. Interestingly, increased $\mathrm{M} / \mathrm{L}$ ratio is associated with the occurrence of cardiovascular events [98]. It is thought that increased $\mathrm{M} / \mathrm{L}$ ratio could be the earliest alteration that occurs in the vasculature [99], and may precede endothelial dysfunction in hypertensive patients. Among the factors that may contribute to the structural alterations of the arterial wall, the variation of myogenic tone (i.e. the intrinsic ability of vessels to constrict in response to increased intraluminal pressure) may exert a significant contribution [100]. Moreover, increased concentration of specific agonists including Ang II and endothelin may also contribute to vasoconstriction and vascular remodelling by increasing the intracellular calcium levels, protein kinases, diacylglycerol, ROS generation [100, 101], and extracellular matrix deposition. These alterations may occur in hypertension as well as in aging. With chronic vasoconstriction, vessels may become embedded in a remodelled extracellular matrix and may not return to their dilated state [3, 100], and in turn, structural narrowing of the lumen may amplify vasoconstriction. Two different types of vascular remodelling have been described: eutrophic and hypertrophic vascular remodelling. Hypertrophic remodelling is characterized by the increased $\mathrm{M} / \mathrm{L}$ together with increased media cross-sectional area, whereas in eutrophic remodelling, the media cross-section does not increase [3, 97], rather smooth muscle cells are reorganized around a smaller lumen which leads to increased M/L. Although both eutrophic and hypertrophic remodelling may occur in the same subject in different vascular beds, these types of vascular remodelling occur in distinct types of arterial hypertension. Eutrophic vascular remodelling is generally found in mild-to-moderate hypertension and is also combined with enhanced apoptosis in the periphery of the vessel $[101,102]$. In experimental animals, eutrophic remodelling is often associated with activation of the RAS. If hypertension is severe or longstanding as well as whether the myogenic reflex and the autoregulatory mechanisms are dysfunctional, the increase in the wall stress may induce hypertrophy. Hypertrophic remodelling of resistance arteries is more prevalent in renovascular hypertension [103], diabetic subjects [104, 105] and acromegalic patients [106], and may also occur in hyperaldosteronism.

\section{Mechanism of Vascular Remodelling}

The molecular mechanisms involved in the remodelling of resistance arteries are not fully understood and are in part similar to those involved in vasculature aging. Several factors may be involved in this process including the activation of RAS, the enhancement of inflammation, growth and profibrotic processes, as well as the modification of VSMCs and extracellular matrix components [107]. The reorganization of the vessel wall components (including collagen, elastin, and other components of extracellular matrix) around a narrower lumen occurs in eutrophic remodelling of resistance arteries, whereas cell growth and deposition of extracellular matrix components contribute to media thickening in hypertrophic remodelling [108-110]. Cell growth and extracellular matrix deposition may result from blood pressure elevation and /or from growth- promoting factors including Ang II, endothelin-1, and cathecolamines. Several experimental data have shown that also the reduced activity of matrix metalloproteinases (MMPs) may play a role in the remodelling of the extracellular matrix in the vascular wall. MMP-1 is reduced in the serum of hypertensive patients with increased vascular level of type I collagen [111] as well as MMP-2 and MMP-3 activity are reduced in spontaneously hypertensive rats [112]. Furthermore, the decrease of MMPs activity in resistance arteries is associated with accumulation of collagen type IV and V and fibronectin [113]. Moreover, in rat mesenteric arteries, MMP-2 is associated with the reduction of the vasoconstrictor effects of the precursor of endothelin-1, the big endothelin-1 [114]. This may contribute to endothelial dysfunction, vasospasm, blood pressure elevation and its related cardiovascular complications. [115]. Moreover, in vascular aging, particularly in large arteries, polymorphisms of MMP-3 and MMP-9 have been associated with vascular remodelling and arterial stiffness [116, 117]. VSMCs are multifunctional cells, which significantly contribute to vascular function and tone. Alteration of VSMCs is associated to arterial remodelling in aging and hypertension through different mechanisms, including hyperplasia, cell growth, apoptosis, cell elongation and reorganization as well as to new production of extracellular matrix proteins, inflammation of the arterial wall, and fibrosis [118-121]. Detachment of VSMCs and endothelial cells, decreased endothelial progenitor cells, and increased microparticles may further contribute to vascular dysfunction and remodelling [111, 122, 123]. Apoptosis is an important mechanism that may contribute to structural remodelling of the arterial wall in aging and hypertension $[111,123]$, although its role is not fully understood. In particular, apoptosis could be either a primary event that may occur in the vasculature in hypertensive con- 
ditions and aging or may be part of a growth-associated compensatory process. Thus an imbalance between growth and apoptosis could be relevant in vascular remodelling.

RAS activation plays a key role in the pathophysiology of vascular remodelling [2]. Ang II may induce vascular remodelling by several mechanisms including vasoconstriction, cell growth, oxidative stress and inflammation. Mainly in hypertensive conditions, Ang II and aldosterone, as well as endothelin-1 enhance the basal superoxide production by the activation of NADPH oxidase and expression of its subunits via the activation of cSrc, PKC (protein kinase C), PLA2 (phospholipase A2) and PLD (phospholipase D) pathways [8, 124-126]. Increased ROS production contributes to the development of vascular dysfunction and arterial remodelling in part by impairing endothelium-derived NO bioavailability as well as by inducing VSMCs proliferation and hypertrophy, collagen deposition in the vascular wall and by inducing the release of pro-inflammatory cytokine and transcription factors (i.e. NF- $\kappa \mathrm{B}$ ). These processes may lead to the functional and structural changes in the circulation, and may participate in the development and progression of atherosclerosis in large arteries.

RAS activity is potentiated by the activation of mineralocorticoid receptors that may contribute to inflammation, fibrosis and vascular dysfunction and damage. In this regard, aldosterone enhances the activity of tissue angiotensinconverting enzyme [125] and up-regulates angiotensin receptors [126] as well as aldosterone induces ROS formation and endothelial dysfunction in several organs including heart and brain, as described in different experimental settings in animal models of cardiovascular disease [126]. Thus, mineralocorticoid antagonism may attenuate these deleterious effects by reducing directly the pro- inflammatory and pro-fibrotic effects of aldosterone [127, 128].

Importantly, inflammation of the vascular wall participates in vascular remodelling by promoting the cell growth and VSMCs proliferation, thus contributing to the accelerated vascular damage in aging and in hypertensive conditions [13], as well as to the initiation and progression of atherosclerosis and the development of cardiovascular and cerebrovascular diseases $[14,15,129,130]$. In the context of inflammation, an important role is played by adhesion molecules (VCAM-1, ICAM-1) which are increased on the endothelial cell membrane at the early stage of the inflammatory process. This leads to the accumulation of monocyte/ macrophages, and lymphocytes [131] in the arterial wall.

Also perivascular fat is involved in vascular remodelling since it exhibits inflammatory changes characterized by increased generation of inflammatory mediators such as $\mathrm{Tu}$ mor Necrosis Factor (TNF)-alpha and increased production of oxidative stress, as well as reduced adiponectin production that may contribute to a contractile phenotype [132, 133].

A large body of evidence indicates that innate immunity may be involved in the mechanisms that contribute to the vascular inflammation, particularly in hypertension. Experimental data showed that the reduction of Treg and the impairment $\mathrm{T}$ effector upregulation are associated with in- creased blood pressure and are involved in the pathogenesis of blood pressure-induced vascular inflammation and cardiovascular remodelling. In this regard, an imbalance between pro-inflammatory subsets of T lymphocytes (Th1, Th2 and $\mathrm{Th} 17$ ) and the anti-inflammatory $\mathrm{T}$ regulatory (Treg) cells might be in part responsible for the inflammatory response in cardiac and metabolic diseases [134]. It has been shown that Ang II and increased ROS production are important modulators of T-cell activation [135-139] as well as Treg cells adoptive transfer may exert a blood pressure lowering effect and modulation of vascular remodelling in mice infused with either AngII [136] or aldosterone [137]. Furthermore, mice deficient in vascular macrophages and in $\mathrm{T}$ and $\mathrm{B}$ - lymphocytes did not present vascular remodelling in response to Ang II- or DOCA-salt [13, 135].

Rarefaction is a different type of remodelling process which occurs in hypertension and aging at the level of smaller arterioles (lumen diameter $<40 \mathrm{u}$ ) [3]. With this process, the density of arterioles per unit of tissue is reduced, thus vascular resistance is increased [140]. In particular, in hypertension, vasoconstriction may induce a functional reduction of small arterioles that may become anatomically permanent, resulting in decreased tissue perfusion.

\section{CONTRIBUTION OF THE INCREASED PERIPHERAL RESISTANCE TO THE REMODELLING OF CONDUIT ARTERIES}

Aging and elevated blood pressure are the two major determinants of increased arterial stiffness in conduit arteries [41]. In patients with long lasting hypertension, or in adult subjects (age $>50$ years), large conduit arteries such as aorta become stiffer because of age-related processes which significantly contribute to systolic blood pressure increase. Interestingly with aging, diastolic blood pressure tends to decrease, leading to increased pulse pressure (PP). In younger individuals, who have a more elastic arterial wall in conduit arteries, PP increases from central to peripheral arteries. This is due to the summation of the incident and the reflected waves more distantly along compliant arteries. Reflected waves originate at different vascular sites from the peripheral vasculature, mainly in resistance sites. In an elastic and compliant vasculature, reflected waves return towards the heart in diastole [141]. With aging, reflected waves return at faster velocity in stiffer arteries, as well as the forward waves from the heart toward the periphery are accelerated, thus the net result is the earlier summation of both forward and reflected waves in the cardiac cycle, leading to the amplification and increase of the aortic systolic pressure. This augmentation contributes to the absence of amplification toward the periphery, which is associated to the increased aortic and peripheral systolic blood pressure and PP. Moreover, it contributes further to the increased stiffness of central elastic arteries. Hypertension may accelerate these mechanisms. Resistance arteries may play a determinant role in this process as the remodelled resistance arteries are not only the site of vascular resistance but possibly the origin of large part of wave reflection in aorta [142]. In turn, increased stiffens and pulsatility in aorta are transmitted to resistance arteries and may contribute to vascular injury in this vascular district [143]. The velocity of propagation of the pressure 
wave along the conduit arteries may be measured through the PVW by tonometric evaluation [142]. Aortic PWV increases with advancing age and is probably the most accurate measure available of aortic stiffness. [144].

A possible association between indices of conduit arterial stiffness and $\mathrm{M} / \mathrm{L}$ ratio of resistance arteries has been described [145]. M/L ratio was significantly related to brachial systolic blood pressure and PP and to central systolic blood pressure and PP. Moreover, a positive correlation was observed between $\mathrm{M} / \mathrm{L}$ ratio and carotid femoral PWV independently of age and mean blood pressure [145]. A link between extracellular matrix molecules and aortic stiffness has also been described. Aortic stiffness is correlated with the expression of genes involved in increased vascular tone and remodelling and in long term sustained contraction (i.e. protein phosphatase-1, the catalytic subunit of myosin light chain phosphatase, members of the family of A kinase anchor protein) [146, 147] as well as with deposition of collagen, fibronectin and non-fibrillar extracellular material in the media. The increase in aortic stiffness and reduced compliance of conduit arteries may contribute to the increase in central pressure and to the development of isolated systolic hypertension (ISH) that represents the most common type of hypertension in the elderly [16].

\section{CONCLUSION}

Hypertension and aging share similar mechanisms of vascular dysfunction. Vascular remodelling, endothelial dysfunction and vascular stiffness are common features in hypertension and aging. Several agonists may contribute to these alterations observed in the vasculature in hypertension and aging. The activation of RAS plays a central role in the genesis of endothelial dysfunction and vascular remodelling by activating redox-sensitive pathways and promoting cell growth and inflammation. Functional and structural alterations of resistance arteries may represent the earliest vascular alterations in hypertensive patients which can contribute to maintain the increased blood pressure values over time, since small arteries and arterioles are the site of vascular resistance to blood flow. Moreover, resistance arteries are also considered the origin of most of the wave reflections contributing to the stiffness of large arteries and the increased central systolic blood pressure in the elderly. Thus, the alterations in the microvasculature may contribute and/or accelerate the aging of conduit arteries. Nevertheless, the relationship between the stiffness of conduit and microvascular dysfunction may be bidirectional, since the transmission of increased arterial pulsatility to resistance arteries could represent also a mechanism of damage at this level.

\section{DISCLOSURE}

The work of the authors was supported by a Grant \# NCDS-2013-00000345 from Fondazione Roma to CS and AF.

\section{CONFLICT OF INTEREST}

The authors confirm that this article content has no conflict of interest.

\section{ACKNOWLEDGEMENTS}

Declared none.

\section{REFERENCES}

[1] Harman D. Role of free radicals in mutation, cancer, aging, and the maintenance of life. Radiat Res 1962; 16: 753-63.

[2] Schiffrin EL, Touyz RM. From bedside to bench to bedside: role of renin angiotensin aldosterone system in remodeling of resistance arteries in hypertension. Am J Physiol Heart Circ Physiol 2004; 287: H435-46.

[3] Schiffrin EL. Remodeling of resistance arteries inessential hypertension and effects of antihypertensive treatment. Am J Hypertens 2004; 17: 1192-200.

[4] Versari D, Daghini E, Virdis A, et al. Endothelium-dependent contractions and endothelial dysfunction in human hypertension. $\mathrm{Br}$ J Pharmacol 2009; 157(4): 527-36.

[5] de Chaves EP, Narayanaswami V. Apolipoprotein E and cholesterol in aging and disease in the brain. Future Lipidol 2008; 3(5): 505-30.

[6] Wang M, Monticone RE, Lakatta EG. Arterial aging: a journey into subclinical arterial disease. Curr Opin Nephrol Hypertens 2010; 19(2): 201-7.

[7] Min LJ, Mogi M, Iwai M, Horiuchi M. Signaling mechanisms of angiotensin II in regulating vascular senescence. Ageing Res Rev 2009; 8(2): 113-21.

[8] Endemann DH, Schiffrin EL. Endothelial dysfunction. J Am Soc Nephrol 2004; 15: 1983-92.

[9] Durier S, Fassot C, Laurant S, et al. Physiological genomics of human arteries quantitative relationship between gene expression and arterial stiffness Circulation 2003; 108: 1845-51.

[10] Yu Y, Fukuda N, Yao EH, et al. Effects of an ARB on endothelial progenitor cell function and cardiovascular oxidation in hypertension. Am J Hypertens 2008; 21(1): 72-7.

[11] Ross R. Atherosclerosis-an inflammatory disease. N Engl J Med 1999; 340: 115-26.

[12] Lerman A, Zeiher AM. Endothelial function: cardiac events. Circulation 2005; 111: 363-8.

[13] De Ciuceis C, Amiri F, Brassard P, et al. Reduced vascular remodeling, endothelial dysfunction, and oxidative stress in resistance arteries of angiotensin II-infused macrophage colony-stimulating factor-deficient mice: evidence for a role in inflammation in angiotensin-induced vascular injury. Arterioscler Thromb Vasc Biol 2005; 25: 2106-13.

[14] Savoia C, Schiffrin EL. Reduction of C-reactive protein and the use of the anti-hypertensives. Vasc Health Risk Manag 2007; 3(6): 975-83.

[15] Savoia C, Schiffrin EL. Inflammation in hypertension. Curr Opin Nephrol Hypertens 2006; 2: 152-8.

[16] Schiffrin EL. Vascular stiffening and arterial compliance. Implications for systolic blood pressure. Am J Hypertens 2004; 17: S3948 .

[17] Kranzhofer R, Schmidt J, Pfeiffer CA, et al. Angiotensin induces inflammatory activation of human vascular smooth muscle cells. Arterioscler Thromb Vasc Biol 1999; 19: 1623-9.

[18] Radziszewski W, Chopra M, Zembowicz A, Gryglewski R, Ignarro LJ, Chaudhuri G. Nitric oxide donors induce extrusion of cyclic GMP from isolated human blood platelets by a mechanism which may be modulated by prostaglandins. Int J Cardiol 1995; 51: 211 20.

[19] Kubes P, Suzuki M, Granger DN. Nitric oxide: an endogenous modulator of leukocyte adhesion. Proc Natl Acad Sci USA 1991; 88: 4651-5.

[20] Mellion BT, Ignarro LJ, Ohlstein EH, Pontecorvo EG, Hyman AL, Kadowitz PJ. Evidence for the inhibitory role of guanosine $3 \mathrm{~V}$, 5 Vmonophosphate in ADP-induced human platelet aggregation in the presence of nitric oxide and related vasodilators. Blood 1981; 57: $946-55$.

[21] Garg UC, Hassid A. Nitric oxide-generating vasodilators and 8bromo-cyclic guanosine monophosphate inhibit mitogenesis and proliferation of cultured rat vascular smooth muscle cells. J Clin Invest 1989; 83: 1774-7. 
[22] Savoia C, Schiffrin EL. Inhibition of the renin angiotensin system: implications for the endothelium. Curr Diabetes Rep 2006; 6: 2748.

[23] Blake JG, Ridker PM. Novel clinical markers of vascular wall inflammation. Circ Res 2001; 89: 763-71.

[24] Lakatta EG. Arterial and cardiac aging: major shareholders in cardiovascular disease enterprises: Part III: cellular and molecular clues to heart and arterial aging. Circulation 2003; 107: 490-7.

[25] Egashira K, Inou T, Hirooka Y, et al. Effects of age on endothelium-dependent vasodilation of resistance coronary artery by acetylcholine in humans. Circulation 1993; 88: 77-81.

[26] Taddei S, Virdis A, Mattei P, et al. Aging and endothelial function in normotensive subjects and patients with essential hypertension. Circulation 1995; 91: 1981-7.

[27] Hatake K, Kakishita E,Wakabayashi I, Sakiyama N, Hishida S. Effect of aging on endothelium-dependent vascular relaxation of isolated human basilar artery to thrombin and bradykinin. Stroke 1990; 21: 1039-43.

[28] Singh N, Prasad S, Singer DR, MacAllister RJ. Ageing is associated with impairment of nitric oxide and prostanoid dilator pathways in the human forearm. Clin Sci (Lond) 2002; 102: 595-600.

[29] Cosentino F, Rubattu S, Savoia C, Venturelli V, Pagannone E, Volpe M. Endothelial dysfunction and stroke. J Cardiovasc Pharmacol 2002; 38(2): S75-8

[30] Busse R, Fleming I. Regulation of endothelium-derived vasoactive autacoid production by hemodynamic forces. Trends Pharmacol Sci 2003; 24: 24-9.

[31] Hongo K, Nakagomi T, Kassell NF, et al. Effects of aging and hypertension on endotheliumdependent vascular relaxation in rat carotid artery. Stroke 1988; 19: 892-7.

[32] Kung CF, Luscher TF. Different mechanisms of endothelial dysfunction with aging and hypertension in rat aorta. Hypertension 1995; 25: 194-200.

[33] Geary GG, Buchholz JN. Selected contribution: effects of aging on cerebrovascular tone and [Ca2+]i. J Appl Physiol 2003; 95: 174654.

[34] Muller-Delp JM, Spier SA, Ramsey MW, Delp MD. Aging impairs endothelium-dependent vasodilation in rat skeletal muscle arterioles. Am J Physiol Heart Circ Physiol 2002; 283: H1662-72.

[35] Csiszar A, Ungvari Z, Edwards JG, et al. Aging-induced phenotypic changes and oxidative stress impair coronary arteriolar function. Circ Res 2002; 90: 1159-66.

[36] Murohara T, Yasue H, Ohgushi M, Sakaino N, Jougasaki M. Age related attenuation of the endothelium dependent relaxation to noradrenaline in isolated pig coronary arteries. Cardiovasc Res 1991; 25: 1002-9.

[37] Chinellato A, Pandolfo L, Ragazzi E, et al. Effect of age on rabbit aortic responses to relaxant endothelium-dependent and endothelium-independent agents. Blood Vessels 1991; 28: 358-65.

[38] Blackwell KA, Sorenson JP, Richardson DM, et al. Mechanisms of aging-induced impairment of endothelium-dependent relaxationsrole of tetrahydrobiopterin. Am J Physiol Heart Circ Physiol 2004; 287: 2448-53.

[39] Shirasaki Y, Su C, Lee TJ, Kolm P, Cline Jr WH, Nickols GA. Endothelial modulation of vascular relaxation to nitrovasodilators in aging and hypertension. J Pharmacol Exp Ther 1986; 239: 861-6.

[40] Barton M, Cosentino F, Brandes RP, Moreau P, Shaw S, Luscher TF. Anatomic heterogeneity of vascular aging: role of nitric oxide and endothelin. Hypertension 1997; 30: 817-24.

[41] Tschudi MR, Barton M, Bersinger NA, et al. Effect of age on kinetics of nitric oxide release in rat aorta and pulmonary artery. $\mathrm{J}$ Clin Invest 1996; 98: 899-905.

[42] Tanabe T, Maeda S, Miyauchi T, et al. Exercise training improves ageinginduced decrease in eNOS expression of the aorta. Acta Physiol Scand 2003; 178: 3-10.

[43] Ranjan V, Xiao Z, Diamond SL. Constitutive NOS expression in cultured endothelial cells is elevated by fluid shear stress. Am J Physiol 1995; 269: H550-5.

[44] Davis ME, Cai H, Drummond GR, Harrison DG. Shear stress regulates endothelial nitric oxide synthase expression through c- -Src by divergent signaling pathways. Circ Res 2001; 89: 1073-80.

[45] Rosen CJ. Growth hormone and aging. Endocrine 2000; 12: $197-$ 201.

[46] Ariznavarreta C, Castillo C, Segovia G, Mora F, Azcoitia I, Tresguerres JA. Growth hormone and aging. Homo 2003; 54: 132-41.
[47] Taddei S, Galetta F, Virdis A, et al. Physical activity prevents agerelated impairment in nitric oxide availability in elderly athletes. Circulation 2000; 101: 2896-901.

[48] Spier SA, Delp MD, Meininger CJ, Donato AJ, Ramsey MW, Muller-Delp JM. Effects of ageing and exercise training on endothelium-dependent vasodilatation and structure of rat skeletal muscle arterioles. J Physiol 2004; 556: 947-58.

[49] Boger RH, Skamira C, Bode-Boger SM, Brabant G, von zur MA, Frolich JC. Nitric oxide may mediate the hemodynamic effects of recombinant growth hormone in patients with acquired growth hormone deficiency. A double-blind, placebo-controlled study. J Clin Invest 1996; 98: 2706-13.

[50] Hamilton CA, Brosnan MJ, Mcintyre M, Graham D, Dominiczak AF. Superoxide excess in hypertension and aging: a common cause of endothelial dysfunction. Hypertension 2001; 37: 529-34.

[51] Harman D. The free radical theory of aging. Antioxid Redox Signal 2003; 5: 557-61.

[52] Finkel T, Holbrook NJ. Oxidants, oxidative stress and the biology of ageing. Nature 2000; 408: 239-47.

[53] Brandes RP, Barton M, Schweitzer G, Phillippens KMH, Mugge A Endothelial-derived superoxide anion in pig coronary arteries: evidence from lucigenin chemiluminescence and histochemical techniques. J Physiol (Lond) 1997; 500: 331-42.

[54] Gorlach A, Brandes RP, Nguyen K, Amidi M, Dehghani F, Busse R. A gp91phox containing NADPH oxidase selectively expressed in endothelial cells is a major source of oxygen radical generation in the arterial wall. Circ Res 2000; 87: 26-32.

[55] Jung O, Schreiber JG, Geiger H, Pedrazzini T, Busse R, Brandes RP. gp91phox-containing NADPH oxidase mediates endothelial dysfunction in renovascular hypertension. Circulation 2004; 109: 1795-1801.

[56] van der Loo B, Labugger R, Skepper JN, et al. Enhanced peroxynitrite formation is associated with vascular aging. J Exp Med 2000; 192: 1731-44.

[57] Xia Y, Zweier JL. Superoxide and peroxynitrite generation from inducible nitric oxide synthase in macrophages. Proc Natl Acad Sci USA 1997; 94: 6954-8.

[58] Zou M, Martin C, Ullrich V. Tyrosine nitration as a mechanism of selective inactivation of prostacyclin synthase by peroxynitrite. Biol Chem 1997; 378: 707-13

[59] Fukai T, Siegfried MR, Ushio-Fukai M, Cheng Y, Kojda G, Harrison DG. Regulation of the vascular extracellular superoxide dismutase by nitric oxide and exercise training. J Clin Invest 2000; 105: 1631-9.

[60] Barton M, Cosentino F, Brandes RP, Moreau P, Shaw S, Luscher TF. Anatomic heterogeneity of vascular aging: role of nitric oxide and endothelin. Hypertension 1997; 30: 817-24.

[61] Goettsch W, Lattmann T, Amann K, et al. Increased expression of endothelin-1 and inducible nitric oxide synthase isoform II in aging arteries in vivo: implications for atherosclerosis. Biochem Biophys Res Commun 2001; 280: 908-13.

[62] Xia Y, Roman LJ, Masters BS, Zweier JL. Inducible nitric-oxide synthase generates superoxide from the reductase domain. J Biol Chem 1998; 273: 22635-9.

[63] Harman D. The free radical theory of aging. Antioxid Redox Signal 2003; 5: 557-61

[64] Finkel T, Holbrook NJ. Oxidants, oxidative stress and the biology of ageing. Nature 2000; 408: 239-47.

[65] Brandes RP, Barton M, Schweitzer G, Phillippens KMH, Mügge A. Endothelial-derived superoxide anion in pig coronary arteries: evidence from lucigenin chemiluminescence and histochemical techniques. J Physiol (Lond) 1997; 500: 331-42.

[66] Gorlach A, Brandes RP, Nguyen K, Amidi M, Dehghani F, Busse R. A gp91phox containing NADPH oxidase selectively expressed in endothelial cells is a major source of oxygen radical generation in the arterial wall. Circ Res 2000; 87: 26-32.

[67] Jung O, Schreiber JG, Geiger H, Pedrazzini T, Busse R, Brandes RP. gp91phox-containing NADPH oxidase mediates endothelial dysfunction in renovascular hypertension. Circulation 2004; 109 : 1795-801.

[68] Vina J, Sastre J, Pallardo F, Borras C. Mitochondrial theory of aging: importance to explain why females live longer than males Antioxid Redox Signal 2003; 5: 549-56.

[69] Burns EM, Kruckeberg TW, Comerford LE, Buschmann MT. Thinning of capillary walls and declining numbers of endothelia 
mitochondria in the cerebral cortex of the aging primate, Macaca nemestrina. J Gerontol 1979; 34: 642-50.

[70] Francia P, delli Gatti C, Bachschmid M, et al. Deletion of p66shc gene protects against age-related endothelial dysfunction. Circulation 2004; 110: 2889-95.

[71] Migliaccio E, Giorgio M, Mele S, et al. The p66shc adaptor protein controls oxidative stress response and life span in mammals. Nature 1999; 402: 309-13.

[72] Weinsaft JW, Edelberg JM. Aging-associated changes in vascular activity: a potential link to geriatric cardiovascular disease. Am J Geriatr Cardiol 2001; 10: 348-54.

[73] Swift ME, Kleinman HK, DiPietro LA. Impaired wound repair and delayed angiogenesis in aged mice. Lab Invest 1999; 79: 1479-87.

[74] Edelberg JM, Tang L, Hattori K, Lyden D, Rafii S. Young adult bone marrow-derived endothelial precursor cells restore agingimpaired cardiac angiogenic function. Circ Res 2002; 90: E89-93.

[75] Foreman KE, Tang J. Molecular mechanisms of replicative senescence in endothelial cells. Exp Gerontol 2003; 38: 1251-7.

[76] Versari D, Daghini E, Virdis A, et al. Endothelium-dependent contractions and endothelial dysfunction in human hypertension. $\mathrm{Br}$ J Pharmacol 2009; 57(4): 527-36.

[77] de Chaves EP, Narayanaswami V. Apolipoprotein E and cholesterol in aging and disease in the brain. Future Lipidol 2008; 3(5): 505-30.

[78] Wang M, Monticone RE, Lakatta EG. Arterial aging: a journey into subclinical arterial disease. Curr Opin Nephrol Hypertens 2010; 19(2): 201-7.

[79] Min LJ, Mogi M, Iwai M, Horiuchi M. Signaling mechanisms of angiotensin II in regulating vascular senescence. Ageing Res Rev 2009; 8(2): 113-21.

[80] Chang E, Harley CB. Telomere length and replicative aging in human vascular tissues. Proc Natl Acad Sci USA 1995; 92: 111904.

[81] Aviv H, Khan MY, Skurnick J, Okuda K, Kimura M, Gardner J, Priolo L, Aviv A. Age dependent aneuploidy and telomere length of the human vascular endothelium. Atherosclerosis 2001; 159: 281-7.

[82] Sherr C, DePinho R. Cellular senescence: mitotic clock or culture shock? Cell Biol 2001; 102: 407-10.

[83] Greene A, Tonellato PJ, Lui J, et al. Microvascular rarefaction and tissue vascular resistance in hypertension. Am J Physiol Heart Circ Physiol 1989; 256: H126-31.

[84] Scalera F, Closs EI, Flick E, et al. Paradoxical effect of L-arginine: acceleration of endothelial cell senescence. Biochem Biophys Res Commun 2009; 386(4): 650-5.

[85] Nilsson PM, Lurbe E, Laurent S. The early life origins of vascular ageing and cardiovascular risk: the EVA syndrome. J Hypertens 2008; 26(6): 1049-57.

[86] Min LJ, Mogi M, Iwanami J, et al. Angiotensin II type 2 receptor deletion enhances vascular senescence by methyl methanesulfonate sensitive 2 inhibition. Hypertension 2008; 51(5): 1339-44.

[87] Camici GG, Sudano I, Noll G, et al. Molecular pathways of aging and hypertension. Curr Opin Nephrol Hypertens 2009; 18(2): 134-7.

[88] Stein M, Boulaksil M, Jansen JA, et al. Reduction of fibrosis related arrhythmias by chronic renin-angiotensin-aldosterone-system inhibitors in an aged mouse model. Am J Physiol Heart Circ Physiol 2010; 299(2): H310-21.

[89] Rivard A, Fabre JE, Silver M, et al. Age-dependent impairment of angiogenesis. Circulation 1999; 99: 111-20.

[90] Koike T, Vernon RB, Gooden MD, Sadoun E, Reed MJ. Inhibited angiogenesis in aging: a role for TIMP-2. J Gerontol A Biol Sci Med Sci 2003; 58: B798-805.

[91] Sadoun E, Reed MJ. Impaired angiogenesis in aging is associated with alterations in vessel density, matrix composition, inflammator response, and growth factor expression. J Histochem Cytochem 2003; 51: 1119-30.

[92] Urbich C, Dimmeler S. Endothelial progenitor cells: characterization and role in vascular biology. Circ Res 2004; 95(4): 343-53.

[93] Scheubel RJ, Zorn H, Silber RE, et al. Age-dependent depression in circulating endothelial progenitor cells in patients undergoing coronary artery bypass grafting. J Am Coll Cardiol 2003; 42: 207380 .

[94] Hill JM, Zalos G, Halcox JP, et al. Circulating endothelial progenitor cells, vascular function, and cardiovascular risk. N Engl J Med 2003; 348(7): 593-600.
[95] ùAgah A, Kyriakides TR, Letrondo N, Bjorkblom B, Bornstein P. Thrombospondin 2 levels are increased in aged mice: consequences for cutaneous wound healing and angiogenesis. Matrix Biol 2004; 22: $539-47$.

[96] Pastore L, Tessitore A, Martinottti S, et al. Angiotensin II stimulates intercellular adhesion molecule-1 (ICAM-1) expression by human vascular endothelial cells and increase soluble ICAM-1 release in vivo. Circulation 1999; 100: 1646-52.

[97] van der Akker J, Schoorl MJ, Bakker ENTP, van Bavel E. Small artery remodeling: current concepts and questions. J Vasc Res 2010; 47: 183-202

[98] Rizzoni D, Porteri E, Boari G, et al. Prognostic significance of small artery structure in hypertension. Circulation 2003; 108: 22305.

[99] Park JB, Schiffrin EL. Small artery remodeling is the most prevalent (earliest?) form of target organ damage in mild essential hypertension. J Hypertens 2001; 19: 921-30.

[100] Sonoyama K, Greenstein A, Price A, et al. Vascular remodeling: implications for small artery function and target organ damage. Ther Adv Cardiovasc Dis 2007; 1(2): 129-37.

[101] Touyz RM, Yao G, Schiffrin EL. c-Src induces phosphorylation and translocation of $\mathrm{p} 47 \mathrm{phox}$ role in superoxide generation by Ang II in human vascular smooth muscle cells. Arterioscler Thromb Vasc Biol 2003; 23: 981-7.

[102] Sharifi AM, Schiffrin EL. Apoptosis in vasculature of spontaneously hypertensive rats effect of an angiotensin converting enzyme inhibitor and a calcium channel antagonists. Am J Hypertens 1998; 11: 1108-16.

[103] Rizzoni D, Porteri E, Guelfi D, et al. Cellular hypertrophy in subcutaneous small arteries of patients with renovascular hypertension. Hypertension 2000; 25: 931-5.

[104] Rizzoni D, Porteri E, Guelfi D, et al. Structural alteration in subcutaneous small arteries of normotensive and hypertensive patients with non insulin-dependent diabetes mellitus. Circulation 2001; 103: $1238-44$.

[105] Endemann DH, Pu Q, De Ciuceis C, et al. Persistent remodeling of resistance arteries in type 2 diabetic patients on antihypertensive treatment. Hypertension 2004; 43: 399-404.

[106] Rizzoni D, Porteri E, Giustina A, et al. Agromegalic patients show the presence of hypertrophic remodeling of subcutaneous small resistance arteries. Hypertension 2004; 43: 561-5.

[107] Savoia C, Schiffrin EL. Vascular inflammation in hypertension and diabetes: molecular mechanisms and therapeutic intervention. Clin Sci 2007; 112: 375-84

[108] Schiffrin EL, Deng LY. Structure and function of resistance arteries of hypertensive patients treated with a b-blocker or a calcium channel antagonist. J Hypertens 1999; 14: 1247-55.

[109] Intengan HD, Thibault G, Li JS, Schiffrin EL. Resistance artery mechanics, structure and extracellular components in spontaneously hypertensive rats effects of angiotensin receptor antagonism and converting enzyme inhibition. Circulation 1999; 100: 2267-75.

[110] Intengan HD, Deng LY, Li JS, Schiffrin EL. Mechanics and composition of human subcutaneous resistance arteries in essential hypertension. Hypertension 1999; 33: 569-74.

[111] Laviades C, Varo N, Fernandez J, et al. Abnormalities of the extracellular degradation of collagen type I in essential hypertension. Circulation 1998; 98: 535-40.

[112] Intengan HD, Schiffrin EL. Structure and mechanical properties of resistance arteries in hypertension role of adhesion molecules and extracellular matrix determinants. Hypertension 2000; 36: 312-8.

[113] Tayebjee MH, MacFadyen RJ, Lip GY. Extracellular matrix biology: a new frontier in linking the pathology and therapy of hypertension? J Hypertens 2003; 21: 2211-8.

[114] Fernandez-Patron C, Radomski MW, Davidge ST. Vascular matrix metalloproteinase-2 cleaves big endothelin-1 yielding a novel vasoconstrictor. Circ Res 1999; 85: 906-11.

[115] Dhaun N, Goddard J, Kohan DE, et al. Role of endothelin-1 in clinical hypertension: 20 years on. Hypertension 2008; 52(3): 4529.

[116] Medley TL, Kingwell BA, Gatzka CD, et al. Matrix metalloproteinase-3 genotype contributes to age-related aortic stiffening through modulation of gene and protein expression. Circ Res 2003; 92: 1254-61.

[117] Medley TL, Cole TJ, Dart AM, et al. Matrix metalloproteinase-9 genotype influences large artery stiffness trough effects on aortic 
gene and protein expression. Arterioscler Trhomb Vasc Biol 2004; 24(8): 1479-84.

[118] Touyz RM, Schiffrin EL. Signal transduction mechanisms mediating the physiological and pathophysiological actions of angiotensin II in vascular smooth muscle cells. Pharmacol Rev 2000; 52: 639-72.

[119] Schiffrin EL, Touyz RM. Multiple actions of angiotensin II in hypertension: benefits of AT1 receptor blockade. J Am Coll Cardiol 2003; 42(5): 911-3.

[120] Nurnberger J, Keflioglu-Scheiber A, OpazoSaez AM, et al. Augmentation index is associated with cardiovascular risk. J Hypertens 2002; 20: 2407-14.

[121] Touyz RM, Deng LY, He G, et al. Angiotensin II stimulates DNA and protein synthesis in vascular smooth muscle cells from human arteries: role of extracellular signal-regulated kinases. J Hypertens 1999; 17: 907-16.

[122] Diep QN, Li JS, Schiffrin EL. In vivo study of AT1 and AT2 angiotensin receptors in apoptosis in rat blood vessels. Hypertension 1999; 34: 617-24.

[123] Intengan HD, Schiffrin EL. Vascular remodeling in hypertension Roles of apoptosis, inflammation, and fibrosis. Hypertension 2001; 38: 581-7.

[124] Touyz RM, Schiffrin EL. Reactive oxygen species in vascular biology: implications in hypertension. Histochem Cell Biol 2004; 122: 339-52.

[125] Harada E, Yoshimura M, Yasue H, et al. Aldosterone induces angiotensin-converting enzyme gene expression in cultured neonatal rat cardiocytes. Circulation 2001; 104: 137-9.

[126] Schiffrin EL, Gutkowska J, Genest J. Effect of angiotensin II on deoxycorticosterone infusion on vascular angiotensin II receptors in rats. Am J Physiol Heart Circ Physiol 1984; 246: H608-14.

[127] Fiebeler A, Schmidt F, Muller DN, et al. Mineralocorticoid receptor affects AP-1 and nuclear factor- $\mathrm{KB}$ activation in angiotensin IIinduced cardiac injury. Hypertension 2001; 37: 787-93.

[128] Virdis A, Neves MF, Amiri F, et al. Spironolactone improves angiotensin-induced vascular changes and oxidative stress. Hypertension 2002; 40: 504-10.

[129] Ross R. Atherosclerosis-an inflammatory disease. N Engl J Med 1999; 340: 115-26.

[130] Libby P. Current concepts of the pathogenesis of the acute coronary syndromes. Circulation 2001; 104: 365-72.

[131] Wung BS, Cheng JJ, Chao YJ, et al. Cyclical strain increases monocyte chemotactic protein-1 secretion in human endothelial cells. Am J Physiol 1996; 270: H1462-8.

[132] Marchesi C, Ebrahimian T, Angulo O, et al. Endothelial NO synthase uncoupling and perivascular adipose oxidative stress and inflammation contribute to vascular dysfunction in a rodent model of metabolic syndrome. Hypertension 2009; 54: 1384-92.
[133] Greenstein AS, Khavandi K, Withers SB, et al. Local inflammation and hypoxia abolish the protective anticontractile properties of perivascular fat in obese patients. Circulation 2009; 119: 1661-70.

[134] Schiffrin EL. T Lynphocytes: a role in hypertension? Curr Opin Nephrol Hypertens 2010; 19: 181-6.

[135] Guzik TJ, Hoch NE, Brown KA, et al. Role of T cell in the genesis of angiotensin II induced hypertension and vascular dysfunction. J Exp Med 2007; 204: 2449-60.

[136] Barhoumi T, Kasal DAB, Li MW, et al. T regulatory lymphocytes prevent angiotensin II-induced hypertension and vascular injury. Hypertension 2011; 57: 469-76.

[137] Kasal DAB, Barhoumi T, Li MW, et al. T regulatory lymphocytes prevent aldosterone-induced vascular injury. Hypertension 2012; 59: 324-30.

[138] Marvar PJ, Thabet SR, Guzik TJ, et al. Central and peripheral mechanisms of T-lymphocyte activation and vascular inflammation produced by angiotensin II-induced hypertension. Circ Res 2010; 107(2): 263-70.

[139] Lob HE, Marvar PJ, Guzik TJ, et al. Induction of hypertension and peripheral inflammation by reduction of extracellular superoxide dismutase in the central nervous system. Hypertension 2010; 55(2): 277-83.

[140] Greene A, Tonellato PJ, Lui J, et al. Microvascular rarefaction and tissue vascular resistance in hypertension. Am J Physiol Heart Circ Physiol 1989; 256: H126-31.

[141] Boutouyrie P, Laurent S, Briet M. Importance of arterial stiffness as cardiovascular risk factor for future development of new type of drugs. Fundam Clin Pharmacol 2008; 22: 241-6.

[142] Safar ME, Rizzoni D, Blacher J, Muiesan ML, Agabiti-Rosei E. Macro and microvasculature in hypertension: therapeutic aspects. J Hum Hypertens 2008; 22(9): 590-5.

[143] Rehman A, Schiffrin EL. Vascular effects of antihypertensive drug therapy Curr Hypertens Rep 2010; 12: 226-32.

[144] Kelly RP, Millasseau SC, Ritter JM, Chowienczyk PJ. Vasoactive drugs influence aortic augmentation index independently of pulse wave velocity in healthy men. Hypertension 2001; 37: 1429-33.

[145] Muiesan ML, Salvetti M, Rizzoni D, et al. Pulsatile hemodynamics and microcirculation: evidence for a close relationship in hypertensive patients. Hypertension 2013; 61: 130-6.

[146] Benigni A, Corna D, Zoja C, et al. Disruption of the Ang II type 1 receptor promotes longevity in mice. J Clin Invest 2009; 119(3): 524-30.

[147] Durier S, Fassot C, Laurant S, et al. Physiological genomics of human arteries quantitative relationship between gene expression and arterial stiffness Circulation 2003; 108: 1845-51. 